\title{
Standards of Head Length and Breadth for Sardinian Population (3-22 Years)
}

\author{
E. Sanna ${ }^{1}$, L. Palmas ${ }^{1}$, M.R. Soro ${ }^{1}$, E. Vallascas ${ }^{1}$, A. De Micco ${ }^{1}$ \\ ${ }^{1}$ Anthropological Science Research Unit, Department of Experimental Biology, University of Cagliari, Sardinia (Italy). \\ E-mail: sannae@unica.it
}

KEYWORDS: Growth charts, head length, head breadth, Sardinia.

\section{Introduction}

Maximum head length and breadth are important measures for the evaluation of cranial and thus brain growth, as well as for clinical examinations to diagnose possible dysmorphology (Aase, 1990). There have been few postnatal growth studies reporting head lengths and breadths in Caucasian populations, which could be used as standards from childhood to adulthood. Moreover, such studies were based on samples that cannot be used as references for all populations since they were different ethnic groups and in different time periods.

In fact, head dimensions vary among populations (Aase, 1990). This is due to genetic and environmental influences producing secular trend effects and microevolutionary changes.

Besides, it has been suggest the opportunity of producing specific head measure standards for the Sardinian population based on a sample of urban Sardinian boys aged 6-13 years (Sanna et al., 2003).

The aims of this study are: a) to test whether international reference values derived from an outdated sample of North Americans of European extraction, namely Canadians (Farkas et al., 1992, 1994) can be used to assess a regional population, in this case Sardinian; b) to produce growth charts for head length and breadth for Sardinian males and females aged 3-22 years.

\section{Materials and Methods}

The cross sectional sample consisted of 9721 subjects of Sardinian origin ( 4884 males and 4837 females), aged 3 to 22 years, measured from 1998 to 2008 in urban and rural municipalities of central-southern Sardinia.An ad-hoc multistage sampling plan was designed in 1997 with the aim of drawing normal standards and determination of the sample size for each age-sex and class. The maximum head length (glabella-opisthocranion) and the maximum head breadth (euryon-euryon) were measured to the nearest millimetre according to Martin and Saller (1957). The adequacy of the measurements was assessed by testing their reliability and accuracy (Frisancho, 1990). Growth percentiles were produced with the LMS method (Cole and Green, 1992; Cole et al., 2002).

\section{Results and Discussion}

The results show that the North American standards are not appropriate for the assessment of Sardinian children. In fact, for both boys and girls for each age class (3-18 years old), the means are always higher in the North American Europeans. For the boys, the only non-significant difference is in the 14 years age class, for the girls, the non-significant differences regards from 16 to 18 years age class. Figures 1 and 2 show the percentiles $\left(3^{\text {rd }}, 50^{\text {th }}, 97^{\text {th }}\right)$ of head length

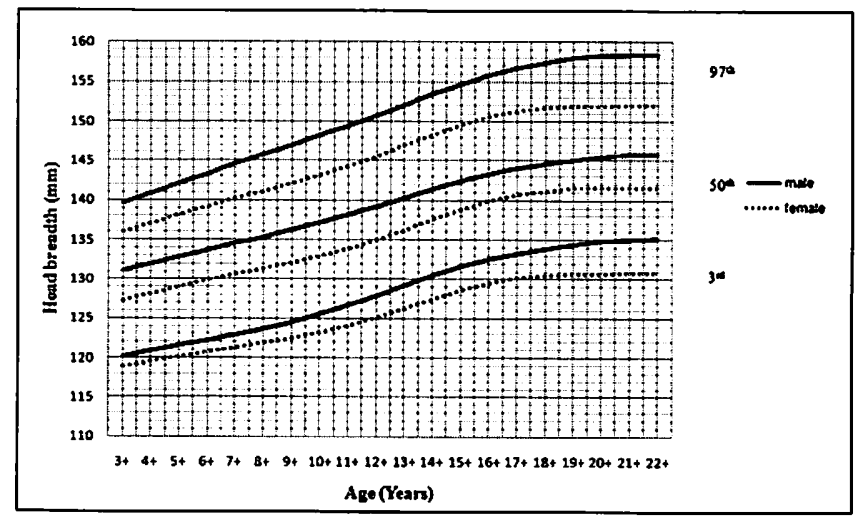

Fig. 1. Percentiles $\left(3^{\text {rd }} ; 50^{\text {hh }}, 97^{\text {th }}\right)$ of head length $(\mathrm{mm})$ of Sardinian males and females from 3 to 22 years old.

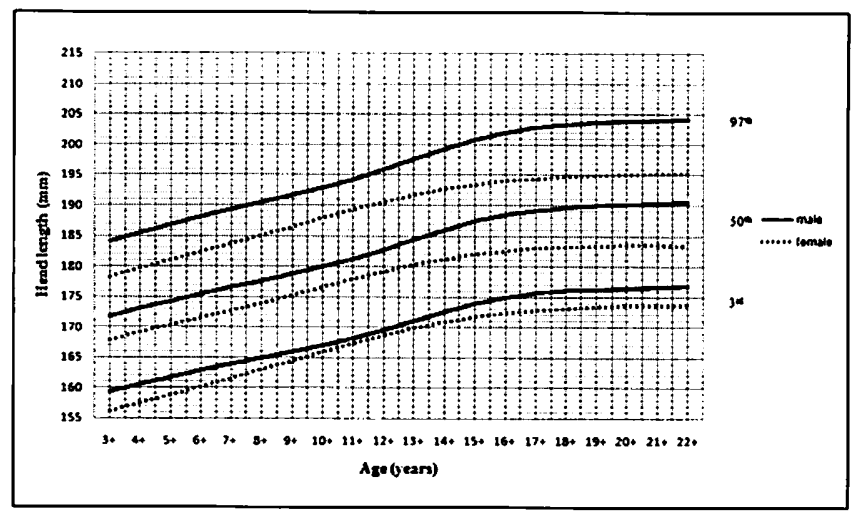

Fig. 2. Percentiles $\left(3^{\text {rd }} ; 50^{\text {th }}, 97^{\text {h }}\right)$ of head breadth $(\mathrm{mm})$ of Sardinian males and females from 3 to 22 years old. 
and breadth by age for Sardinian males and females (LMS method), respectively.

The results show that the North American standards are not appropriate for the assessment of Sardinian children. For the Sardinian population, specific regional growth charts should be used to correctly evaluate the normal range and the cut-off points of the extreme percentiles. Besides, considering the diversity of head measurements among populations (Farkas and Deutsch, 1996; Zhuang et al., 2010), it is likely that specific standards for head measures are also needed for other European ethnic groups.

\section{References}

Aase J.M. 1990. Diagnostic dysmorphology. Plenum Medical Book Company, New York.

Cole T.J. 2002. Growth references and the LMS method. In: Gilli G., Schell L., Benso L. (Eds.), Human growth from conception to maturity. Smith-Gordon, London: 69-77.
Cole T.J., Green P.J. 1992. Smoothing reference centile curves:The LMS method and penalized likelihood. Stat. Med., 11: 1305 1319.

Farkas L.G., Deutsch C.K. 1996. Anthropometric determination of craniofacial morphology. Am. J. Med. Genet, 65: 1-4.

Farkas L.G., Hreczko T.A., Katic M.J. 1994. Craniofacial norms in North American Caucasians from birth (one year) to young adulthood. In: Farkas L.G. (Ed.) Anthropometry of the head and face. Raven Press, New York.

Frisancho A.R. 1990. Anthropometric standards for the assessment of growth and nutritional status. The University of Michigan Press, Ann Arbor.

Martin R., Saller K.1957. Lehrbüch der Antropologie. Fischer Verlag, Stuttgart.

Sanna E., Palmas L., Tedesco N., Floris G. 2003. The need of specific standards for head dimensions in urban Sardinian boys. Anthropol.Anz., 61: 245-251.

Zhuang Z., Landsittel D., Benson S., Roberge R., Shaffer R. 2010. Facial anthropometric differences among gender, ethnicity, and age groups. Ann. Occup. Hyg., 54: 391- 402. 